This is an Accepted Manuscript of an article published by Taylor \& Francis in International Journal of Polymeric Materials and Polymeric Biomaterials, Volume 68, 2019 - Issue 4 available online: https://doi.org/10.1080/00914037.2018.1429435 


\section{The effect of composition of a polymeric coating on the biofilm formation of bacteria and filamentous fungi}

Nikola Mikušová ${ }^{1}$, Kateřina Nechvilová ${ }^{2}$, Andréa Kalendová ${ }^{2}$, Tereza Hájková ${ }^{2}$, Zdenka

Capáková ${ }^{1}$, Ita Junkar ${ }^{3}$, Marián Lehocký ${ }^{1}$, Miran Mozetič ${ }^{3}$, Petr Humpolíček ${ }^{1,4, *}$

1 Centre of Polymer Systems, Tomas Bata University in Zlin, Tr. Tomase Bati, 5678, 760

01 Zlin, Czech Republic

e:mail:mikusova@cps.cz, capakova@cps.cz, lehocky@cps.cz

2 Faculty of Chemical Technology, Institute of Chemistry and Technology of

Macromolecular Materials, Department of Paints and Organic Coatings, Studentská 95,

52310 Pardubice, Czech Republic

e:mail: Andrea.Kalendova@upce.cz, katerina.nechvilova@student.upce.cz, tereza.hajkova1@student.upce.cz

3 Josef Stefan Institute, Jamova 39, Ljubljana 1000, Slovenia, e-mail: ita.junkar@ijs.si, miran.mozetic@ijs.si

4 Polymer Centre, Faculty of Technology, Tomas Bata University in Zlin, 762 72, Zlin, Czech Republic

* Correspondence: humpolicek@utb.cz; Tel.: +420 576031 307,+420 576038035

Abstract: Functionality of polymeric coating, especially in terms of anti-corrosive properties and stability, can be negatively influenced by formation of either bacterial and/or fungal biofilm on its surface. Inhibition of biofilm formation together with improved anti-corrosive properties can be achieved by modification of pigments. Herein, the commercial epoxy-ester resin based polymeric coating was filled with various pigments (natural silicon dioxide diatomite, natural wollastonite, tungstate and molybdate). Pigments was modified by conducting polymers (polyaniline phosphate, polypyrrole phosphate, poly(pphenylenediamine) phosphate and $\mathrm{ZnFe}_{2} \mathrm{O}_{4}$ ). Impact of modified pigments on the surface energy and formation of bacterial and fungal biofilm were tested. The use of various biofilm forming species of both the bacteria and fungi leads to the filling of knowledge gap about their behavior on polymeric coatings.

Keywords: polymeric coating; pigment; biofilm formation; bacteria; fungi. 


\section{Introduction}

Planktonic or biofilm mode of growth is basic parameter influencing the interaction between the material surfaces and microorganism. Biofilm is defined as an aggregation of microbial cells on a surface, embedded within an extracellular polymeric substance [1]. Biofilm formation on the surface can lead to the change of various surface properties e.g. the transparency, surface energy, conductivity or degradation of material resulting in change of its composition. As a consequence, biofilms currently represent a significant problem in many industrial fields [2], especially membrane separation processes [3], corrosion of machine components [4], production of recycled paper [5] as well as in biomedical applications, where biofilms might cause orthopaedic infections [6] or damage of implants [7]. In order to address these issues, the preparation of "anti-biofouling" surfaces are in the center of attention.

Conducting polymers (herein after referred to also as "CPs") are in the center of attention thanks to their unique chemical and physical properties $[8,9,10]$ e.g. high doping level and rapid electrochemical switching [11,12]. Wide-ranging applications include manufacturing of batteries, capacitors, sensors, anti-corrosive protection, memory devices, and drug release system $[13,14,15,16,17]$.

One of interesting property of CPs is their ability to work as anti-corrosive agents [18], for instance in coating. It is assumed that the CPs passivate metals by forming a protective oxide on the surface of the metal, thereby reducing corrosion [19]. The most extensively studied CPs are polyaniline, polypyrrole, and poly(p-phenylenediamine), which have been applied with success in certain applications e.g. active anti-corrosion agent for metallic materials by means of organic polymeric coatings [20,21, 22]. Composite pigments combining the pigment (core) covered with a CP layer (shell), may eventually supersede toxic pigments containing lead or hexavalent chromium [23]. The advantages of such core/shell pigments with CP layers compare to CPs alone are as follows: a) increase in the number of contact sites in the polymeric coating; b) promotion of a synergistic effect exhibited by the $\mathrm{CP}$ and pigment core in anti-corrosion efficiency; and c) improvement in the physical properties of the polymeric coating. Polymeric coatings containing CPs solve the issue of providing anti-corrosion protection through organic coatings, these being referred to as "smart coatings".

The other reason for interest in polymers is their ability to act as an "anti-biofouling" coating [24]. Such surfaces can be composed of CPs [25] that further influence surface properties and express antibacterial activity [26]. Herein, the anti-biofouling properties and the surface energy of polymeric coatings including pigments modified by CPs were investigated. 


\section{Results and discussion}

\subsection{Scanning electron microscopy}

The scanning electron microscopy (SEM) was used for evaluation of the surface and morphology of pigment particles (Fig. 1) and polymeric coatings (Fig. 2) separately because at low concentration of pigments the SEM analysis remained unchanged. The magnification of individual present figures depended on particle size given by its structure and type of use. The surface modification using conductive polymers did not change the morphology or particle size and the pigments tended to form clumps, which had to be separated during dispersion in a polymeric binder. Coatings pigmented with 1\% VCP (Volume Concentration of Pigment had the same surface morphology. The pigments were applied in a polymeric binder by high dispersion, which forms a smooth and sintered film after application.

\subsection{Surface energy}

Ability of bacteria and fungi to form a biofilm on any surface is influenced by numerous parameters from which the surface energy plays a crucial role [27]. The surface energy of all prepared polymeric coatings is summarized in the Table 1. It is clear that pigmentation increased the surface energy of polymeric coatings. It is known that CPs and some pigments extend the drying time of polymeric coatings and their use make a coating more plastic-like and decrease the hardness of the surface. If pigments are treated with CPs, the effects of the individual components are synergistic. Herein, surface treatment of $\mathrm{SiO}_{2}$ with a $\mathrm{CP}$ was accompanied by a rise in surface energy, whereas surface modification of $\mathrm{CaSiO}_{3}$ and $\mathrm{Fe}_{2} \mathrm{WO}_{6}$ brought about a slight drop in surface energy. Pigments differ in their acid-base and morphological properties, while $\mathrm{CaSiO}_{3}$ is basic and its particles are clearly needle-shaped, in contrast with $\mathrm{SiO}_{2}$, which is neutral to slightly acid with irregular particles, possessing very diverse shapes. Pigments based on molybdenum and tungsten exhibit relatively regular-shaped particles. Modifying the surface of the pigments with CPs failed to alter the shape of the particles appreciably. In actual fact, the pigments largely become more porous, showing a complex surface and exhibiting binding sorption properties.

The differences in surface energy of each coating pertain to the nature of the pigment (chemical composition, particle shape), as well as to the presence of the CP. The effect of the CP and of the pigment on surface energy cannot be directly inferred from the value found for any individual concentration. The highest values for surface energy of the polymeric coatings were primarily observed in samples where the pigment surface had been modified with PPDA, except for the sample $\mathrm{CaSiO}_{3} / \mathrm{PPDA}$. The lowest surface energy was observed for the reference 
material WorléeDur D 46, i.e. merely the epoxy-ester resin-based film itself with no added pigment.

\subsection{Bacterial biofilm}

The creation of biofilm on any surface is a crucial factor for utilizing of materials in a variety of industrial applications. Table 2 describes biofilm formation by two biofilm-forming bacteria species on coating samples with different composition. The number of bacterial cells and related biofilm formation on the tested surfaces was affected by the composition of polymeric coating. Generally, the weakest biofilm formation was observed on surfaces containing the pigment $\mathrm{Fe}_{2}\left(\mathrm{MoO}_{4}\right)_{3}$, especially when modified with PPY in case of $P$. aureginosa or when modified with PPDA in case of $B$. cereus. Polymeric coatings with modified $\mathrm{CaSiO}_{3}$ also reduced biofilm formation with regard to $P$. aureginosa, especially in case of $\mathrm{CaSiO}_{3} / \mathrm{ZnFe}_{2} \mathrm{O}_{4}$. However, all mentioned differences were insignificant.

On the other hand, the biofilm formation on $\mathrm{SiO}_{2} / \mathrm{PANI}$ was remarkable as growth of both bacterial strains was significantly higher (by two orders of magnitude) compare to all other samples. The differences between $\mathrm{SiO}_{2}$ and $\mathrm{CaSiO}_{3}$ pigments from a chemical point of view are primarily in their $\mathrm{pH}$ : while $\mathrm{SiO}_{2}$ is of medium acidity, $\mathrm{CaSiO}_{3}$ is strongly basic. Their particle shapes were appreciably different as well. $\mathrm{SiO}_{2}$, which possesses porous particles of a large, specific surface area, exerts a greater effect on the surface of the polymeric coatings; moreover, a layer of PANI is deposited in a stronger and more porous layer owing to the suitable properties of the pigment $[28,29]$. The film surface produced could also be rougher and more complex. The resulting $\mathrm{SiO}_{2} / \mathrm{PANI}$ particles exhibit a larger, specific surface area and more porous structure, also in comparison with other surface-modified $\mathrm{SiO}_{2}$ pigments. The $\mathrm{SiO}_{2}$ pigment coated with PPDA also demonstrated slightly more extensive biofilm formation, although this was not significantly higher than the other pigment types.

\subsection{Filamentous fungi biofilm}

Under real conditions, the surface of any material is not exposed only to bacterial cells, but also to fungal cells. Nevertheless, the number of studies focused on fungal biofilm is highly limited. Therefore, herein, the authors mimicked real conditions by inoculating a mixed culture of four fungal species. It was tested if the fungi overgrowth on the polymeric coating from the surrounding agar (from which can fungi draw a nutrients) or if they are even able to form a biofilm without contact of filaments with agar. Therefore, cultivation on complete (MEBB) and incomplete agar was tested (Table 3). 
On MEBB, it was determined that the greatest degree of growth occurred in the case of $\mathrm{CaSiO}_{3} / \mathrm{PPDA}$, while the least growth was seen on the surface with the $\mathrm{CaSiO}_{3}$. More intensive biofilm formation on MEBB - compared with the reference sample - was observed almost on all surfaces, except $\mathrm{SiO}_{2}, \mathrm{SiO}_{2} / \mathrm{PANI}$ and $\mathrm{SiO}_{2} / \mathrm{ZnFe}_{2} \mathrm{O}_{4}$. The effect of $\mathrm{SiO}_{2}$ is not connected to the surface energy of final material as they were similar to reference.

The test performed on incomplete agar should reveal if the fungi were able to use any of tested materials as source of nutrients. Based on the results presented in Table 3 we can conclude that biofilm overgrowth and formation on all tested polymeric coatings was lower than on reference. The fungi were not therefore able to use the polymeric coatings as source of nutrients. The lowest extent of biofilm formation was observed in the sample $\mathrm{SiO}_{2} / \mathrm{ZnFe}_{2} \mathrm{O}_{4}$.

\section{Materials and Methods}

\subsection{Sample preparation}

The commercial epoxy-ester resin Worleédur D46 (composition: 60\% epoxide, 40\% conjugated fatty acid, tung oil; density: $1.07 \mathrm{~g} \mathrm{~cm}^{-3}$; solvent: xylene) was used as the binder for preparing the polymeric coating. Inorganic pigments coated with layers of the CP were applied as chemically active pigments.

The pigments comprised the following: natural silicon dioxide diatomite $\left(\mathrm{SiO}_{2}\right)$, natural wollastonite $\left(\mathrm{CaSiO}_{3}\right)$, tungstate $\left(\mathrm{Fe}_{2} \mathrm{WO}_{6}\right)$ and molybdate $\left(\mathrm{Fe}_{2}\left(\mathrm{MoO}_{4}\right)_{3}\right)$. Tungstate and molybdate pigments were prepared by solid-phase reaction [30] and included either iron(III) tungstate $\left(\mathrm{Fe}_{2} \mathrm{WO}_{6}\right)$ or iron(III) molybdate $\mathrm{Fe}_{2}\left(\mathrm{MoO}_{4}\right)_{3}$. The pigments were modified with following anti-corrosion agents: polyaniline phosphate (PANI), polypyrrole phosphate (PPY), poly(p-phenylenediamine) phosphate (PPDA), or $\mathrm{ZnFe}_{2} \mathrm{O}_{4}$ mixed oxide $\left(\mathrm{ZnFe}_{2} \mathrm{O}_{4}\right)$. The final composition of the coatings used are summarized in Table 4.

The composite pigments consisted of crystalline fractions (core) and X-ray amorphous fractions (shell). The pigments also contained some trace amounts of $\mathrm{SO}_{3}$ - due to the use of the acid and/or the initiator (up to 1-2 wt.\%). Further, the surface and the shape of pigments, and the morphology of polymeric coatings were examined with the SEM analysis (JEOL-JSM 5600 LV, Japan).

The pigments were coated with a PANI phosphate layer, the method involving oxidative precipitation volume polymerization of aniline [31]. For this, $9.06 \mathrm{ml}$ of aniline $\left(\mathrm{C}_{6} \mathrm{H}_{7} \mathrm{~N}\right.$, Fluka, Switzerland) was dissolved in $250 \mathrm{ml}$ of distilled water acidified with $0.8 \mathrm{M} \mathrm{H}_{3} \mathrm{PO}_{4}$ (orthophosphoric acid, Lachema, Czech Republic). This solution was stirred and the pigment was added. A solution of $0.25 \mathrm{M}$ ammonium peroxodisulphate $\left(\mathrm{NH}_{4}\right)_{2} \mathrm{~S}_{2} \mathrm{O}_{8}$ (Lach-Ner, Czech 
Republic) was also prepared, and the polymerization reaction was initiated. Stirring continued for 1 hour, after which the mixture was allowed to stand till the next day for the polymerization reaction to complete. The following day, the solids were filtered out and rinsed with $0.2 \mathrm{M}$ phosphoric acid followed by acetone. The pigment particles coated with the PANI overlayer were dried in air and then at $60^{\circ} \mathrm{C}$ in a laboratory dryer. The composite particles contained about 10 wt.\% PANI (emeraldine) phosphate. Pigments modified with layers of poly(pphenylenediamine) PPDA or polypyrrole phosphate were prepared likewise by using pphenylenediamine $\left(\mathrm{C}_{6} \mathrm{H}_{8} \mathrm{~N}_{2}\right)$ and pyrrole $\left(\mathrm{C}_{4} \mathrm{H}_{5} \mathrm{~N}\right)$, respectively, (both Sigma-Aldrich) as the initiating substances. Diatomite $\mathrm{SiO}_{2}$ and wollastonite $\mathrm{CaSiO}_{3}$ were modified with a layer of zinc ferrite, deposited on them from a ferrous salt and a zinc salt in an aqueous medium during urea hydrolysis in a basic system [32].

The model coatings were prepared by dispersing the powdered pigments in the liquid binder via a Dispermat CV pearl mill (WMA Getzmann GmbH, Verfahrenstechnik, Germany) at

$3000 \mathrm{rpm}$ for 45 minutes. Pigment volume concentration (PVC $\left.\left(\phi_{i}\right)\right)$ was $1 \%$ in all cases except the $\mathrm{Fe}_{2} \mathrm{WO}_{6} / \mathrm{PANI}$ system, where a concentration as high as $15 \%$ was applied. The polymeric (organic) coatings were obtained by applying the liquid system to a glass substrate, where they dried under the binder oxypolymerisation reaction and the physical and chemical mechanisms. Samples for measurement were prepared in thin layers by spin coating on a spin coater (Spinner, POLOS300 Advanced; Netherlands). Slides of 26 × 26 × $1 \mathrm{~mm}$, previously washed and degreased with chloroform, were utilized for the spin coating procedure. The application rate was approximately $7000 \mathrm{rpm}$ for $1 \mathrm{~min}$. of drying. The samples were conditioned in an airconditioned room $\left(2{ }^{\circ} \mathrm{C}, 50 \%\right.$ relative humidity) for 21 days prior to testing.

\subsection{Evaluation of surface energy}

Contact angle data were obtained using a Surface Energy Evaluation System (SEE system) from Advex Instruments (Czech Republic). Deionized water, ethylene glycol, and diiodomethane were utilized as the testing liquids. The volume of droplets was set to $5 \mu 1$ for all experiments to avoid errors connected with gravity acting on the sessile drop. Five contactangle readings were averaged to obtain one representative value. The free energy of the substrate surface was evaluated by the Lifshitz-van der Waals "acid-base" model [33]. Additionally, total surface energy $(\gamma t o t)$ as well as its components, disperse $(\gamma L W)$ and acidbase $(\gamma \mathrm{AB})$ (polar) components are reported. For calculated dispersive and polar components were used equations: $\gamma^{\text {tot }}=\gamma^{\mathrm{LW}}+\gamma^{\mathrm{AB}}$ and $\gamma^{\mathrm{AB}}=2 \sqrt{\gamma^{+} \gamma^{-}}$.

\subsection{Formation of bacterial biofilm}


Prior to testing of bacterial biofilm formation, the polymeric coatings were sterilized by exposure to a UV-light $(258 \mathrm{~nm})$ for $30 \mathrm{~min}$. The test of bacterial biofilm formation was performed with the following biofilm-positive bacterial strains: Bacillus cereus (CCM 2010) and Pseudomonas aeruginosa (CCM 3955); purchased from the Czech Collection of Microorganisms (CCM) in Brno, the Czech Republic. The bacteria were incubated in a incubator (Memmert INE 600, Switzerland) for 24 hours, with Bacillus cereus at $37^{\circ} \mathrm{C}$ and Pseudomonas aeruginosa at $30^{\circ} \mathrm{C}$. The bacteria grew on Nutrient agar No. 2 with glucose (HiMedia, India). The initial bacterial inocula were prepared by seeding the strains to the physiological solution with turbidity $(\tau=2)$ in adherence with the McFarland scale [34], using a densitometer (Biosan, Latvia).

The process of quantifying the biofilm with bacteria followed a procedure described previously [35]. In brief, $210 \mu 1$ Tryptone Soya Broth (Himedia, India) containing $20 \mu 1$ bacterial inocula was added to each well on a microtiter plate and incubated at $30^{\circ} \mathrm{C}$ and $37^{\circ} \mathrm{C}$ for $48 \mathrm{~h}$, in accordance with the requirements of the individual strains. After incubation, the content of each dish was carefully removed, and the tested surface was rinsed with a physiological solution and dried in air. Determining the level of adenosine triphosphate (ATP) involved using the ATP Biomass Kit HS by Biotherma (Sweden). In order to release the cells from the surface, ultrapure water with Extractant B/S (BioThema, Sweden) at the ratio 1:1 was added to each sample. The solution was mixed with ATP Reagent HS + diluent B solution (BioThema, Sweden) at the ratio 1:4, transferred to a cuvette, and then light emission $\left(I_{s m p 1 / 2}\right)$ was measured on a luminometer (Turner BioSystems). Following this, the content of the cuvette was supplemented with $10 \mu 1$ of $100 \mathrm{nmol}^{-1}$ ATP Standard (BioThema,Sweden), containing a known quantity of ATP, and light emission was repeatedly measured $\left(I_{s m p+s t d}\right)$. The amount of ATP (pmol) in the sample was calculated using the equation $A T P_{s m p}=I_{s m p 1} /\left(I_{s m p+s t d}-I_{s m p 2}\right)$, and the ATP level was subsequently expressed as the number of $E$. coli cells with aid of a calibration curve. The test was performed in quadruplicates.

\subsection{Formation of filamenous fungi biofilm}

Mixed culture of following filamentous fungal strains: Aspergillus niger (CCM 8155), Gliocladium virens (CCM 8042), Paecilomyces variotii (CCM F-398) and Trichoderma viridae (F-486), all purchased from the Czech Collection of Microorganisms (CCM) in Brno, the Czech Republic, were used. The fungal strains were cultivated using malt-extract bouillon broth (MEBB, Himedia, India) solidified with rich-nutrient agar $\left(20 \mathrm{~g} \mathrm{l}^{-1}\right)$. Poor-nutrient agar contained the following components: $\mathrm{NaNO}_{3} 1 \mathrm{~g} \mathrm{l}^{-1}, \mathrm{NH}_{4}\left(\mathrm{SO}_{4}\right)_{2} 1 \mathrm{~g} \mathrm{l}^{-1}, \mathrm{~K}_{2} \mathrm{HPO}_{4} 1 \mathrm{~g} \mathrm{l}^{-1}, \mathrm{KCl}$ 
$0.5 \mathrm{~g} \mathrm{l}^{-1}, \mathrm{MgSO}_{4} .7 \mathrm{H}_{2} \mathrm{O} 0.5 \mathrm{~g} \mathrm{l}^{-1}, \mathrm{FeSO}_{4} 0.01 \mathrm{~g} \mathrm{l}^{-1}$, soya peptone $0.1 \mathrm{~g}^{-1}$, agar $18 \mathrm{~g} \mathrm{l}^{-1}$ and trace element solution $1 \mathrm{ml}[36]$.

Prior to testing of fungal biofilm growth, the polymeric coatings were sterilized by exposure to a UV-light $(258 \mathrm{~nm})$ for $30 \mathrm{~min}$. Rich nutrient agar was inoculated with $0.1 \mathrm{ml}$ spore suspension of the individual fungal strains. This was carried out by the following: the given mould was wiped three times by a loop in tubes with $3 \mathrm{ml}$ sterile saline solution. The polymeric coatings were carefully placed on the surface of the nutrient media. The suspensions prepared of fungal spores were applied using sterile cotton sticks around the edges of the coatings.

All samples were incubated at $25^{\circ} \mathrm{C}$ for 42 days, and images after $7,14,21,28,35$ and 42 days of cultivation were taken. The grip was overlapped through the images to determine the overgrowth and formation of the biofilm (see Fig. 3). The individual squares of the grid, which either did or did not contain fungal biofilm, were counted. The overgrowth and formation were expressed as the percentage of area covered with fungal mycelium compare to non-covered area. The growth of filamentous fungi on the nutrient-poor agar was also subsequently analyzed in the same way. All tests were performed in duplicates [26].

\section{Conclusions}

By combining the use of polymeric coatings and modified pigments, it is possible to develop a new material for various applications where anticorrosion properties are expected. The biofilm forming bacterial and fungal strains were utilized to detect their ability to grow on modified polymeric films. Additionally, in order to further knowledge on microorganisms attaching themselves to such surfaces, the surface energy was determined. Results contribute to understanding of relation between conducting polymers, polymeric coatings and biofilms of bacteria and especially fungi which was not previously studied.

Acknowledgments: This work was supported by the Ministry of Education, Youth and Sports of the Czech Republic - Programme NPU I [LO1504]. The authors are also grateful to the Czech Science Foundation [17-05095S]. The author, Nikola Mikušová, acknowledges the support of an internal Grant from TBU in Zlín [IGA/CPS/2018/001] financed from funds of specific academic research.

\section{Author Contributions:}

Kateřina Nechvilová, Andréa Kalendová, Tereza Hájková: have prepared the polymeric coatings based on commercial epoxy-ester resin containing pigments. 
Nikola Mikušová, Zdenka Capáková, Ita Junkar, Marián Lehocký, Miran Mozetic, Petr

Humpolíček: were responsible persons for biological testing of prepared polymeric coatings (biofilm formation of bacteria and fungi) and surface energy measurement.

Conflicts of Interest: The authors declare that there is no conflict of interest.

Sample Availability: Samples of the compounds are available from the authors

\section{References}

1. Vu, B., Chen, M., Crawford, R. J., Ivanova, E. P., Molecules 14, 2535-2554 (2009).

2. Garrett, T. R., Bhakoob, M., Zhang, Z., Prog. Nat. Sci. 18 (19), 1049-1056 (2008).

3. Liu, S., Fang, F., Wu, J., Zhang, K., Desalination 375, 121-128 (2015).

4. Torres, C. E., Gibello, A., Nande, M., Martin, M., Blanco, A., Appl. Microbiol. Biotechnol. 75 (5), 889-897 (2009).

5. Torres, C. E., Lenon, G., Craperi, D., Wilting, R., Blanco, A., Appl. Microbiol. Biotechnol. 92 (1), 95-103 (2011).

6. Costerton, J. W., Clin. Orthop. Relat. R. 437, 7-11 (2005).

7. Pavithra, D., Doble, M., Biomed. Mat. (3), 034003 (2008).

8. Das, T. K., Prusty, S., Polym-Plast. Technol. 51 (14), 1487-1500 (2012).

9. Moyen, E., Hama, A., Ismailova, E., Assaud, L., Malliaras, G., Hanbücken, M., Owens, R. M., Nanotechnology 27 (7), 074001 (2016).

10. Luo, S. C., Polym. Rev. 53 (3), 303-310 (2013).

11. Frackowiak, E., Khomenkob, V., Jurewicz, K., Lota, K., Béguin, F., J. Power Sources 153 (2), 413-418 (2016).

12. Mastragostino, M., Arbizzani, C., Soavi, F., J. Power Sources 97-98, 812-815 (2001).

13. Deshpande, P. P., Jadhav, N. G., Gelling, V. J., Sazou, D. J., Coat. Technol. Res. 11 (4), 473-494 (2014).

14. Sengodu, P., Deshmukh, A. D., RSC Adv. 5 (52), 42109-42130 (2015).

15. Ates, M., Mat. Sci. Eng. C - Mater. 33 (4), 1853-1859 (2013).

16. Ramya, R., Sivasubramanian, R., Sangaranarayanan, M. V., Electrochim. Acta 101, 109-129 (2013).

17. Otero, T. F., Martinez, J. G., Arias-Pardilla, J., Electrochim. Acta 84, 112-128 (2012).

18. Kalendová, A., Sapurina, I., Stejskal, J., Veselý, D., Corros. Sci. 50 (12), 3549-3560 (2008).

19. Sitaram, S. P., Stoffer, J. O., O’Keefe, T. J., J. Coating. Technol. 69, 65-69 (1997). 
20. Armelin, E., Oliver, R., Liesa, F., Prog. Org. Coat. 59 (1), 46-52 (2007).

21. Deshpande, P., Vagge, S., Jagtap, S., Bulg. Chem. Commun. 44 (4), 318-323 (2012).

22. Sathiyanarayanan, S., Muthukrishnan, S., Venkatachari, G., Prog. Org. Coat. 53, 297-301 (2005).

23. Sambyal, P., Ruhi, G., Bhandari, H., Dhawan, S. K., Surf. Coat.Tech. 272, 129-140 (2015).

24. Au, K. M., Zenghai, L. U., Matcher, S. J., Armes, S. P., Biomaterials 34 (35), 8925-8940 (2013).

25. Tada, S., Inaba, C., Mizukami, K. et al., Macromol. Biosci. 9, 63-70 (2009).

26. Mikušová, N., Humpolíček, P., Růžiččka, J., Capáková, Z. et al., Chem. Pap. 71 (2), 505-512 (2017).

27. Feng, G., Cheng, Y., Wang, S. Y., Borca-Tasciuc, D. A., Worobo, R. W., Moraru, C. I., Npj Biofilms and Microbiomes 1, 15022 (2012).

28. Veselý, D., Kalendová, A., Kalenda, P., Prog. Org. Coat. 68, 173-179 (2010).

29. Liang, J. Z., Li, B., Ruan, J. Q., Polym. Test. 42 (3), 185-191 (2015).

30. Trojan, M., Brandova, D., Solc, Z., Thermochim. Acta 110, 343-358 (1987).

31. Stejskal, J., Gilbert, R. G., Pure Appl. Chem. 74, 857-867 (2002).

32. Kalendová, A., Pigm. Resin Technol. 31 (4), 216 - 225 (2002).

33. Wu, W., Giese, R. F. Jr., Van Oss, C. J., Langmuir 11 (1), 379-382 (1995).

34. McFarland, J., JAMA- J. Am. Med. Assoc. 49 (14), 1176 (1907).

35. Koutny, M., Sancelme, M., Dabin, C. et al., Polym. Degrad. Stabil. 91 (7), 1495-1503 (2006).

36. Muchova, M., Ruzicka, J., Julinova, M., Dolezalova, M., Houser, J., Koutny, M., Bunkova, L., Water Sci. Technol. 60, 965-973 (2009). 